\title{
Genealogía de la Educación Inicial en el Ecuador
}

\section{Eva Johanna Pautasso Solís*}

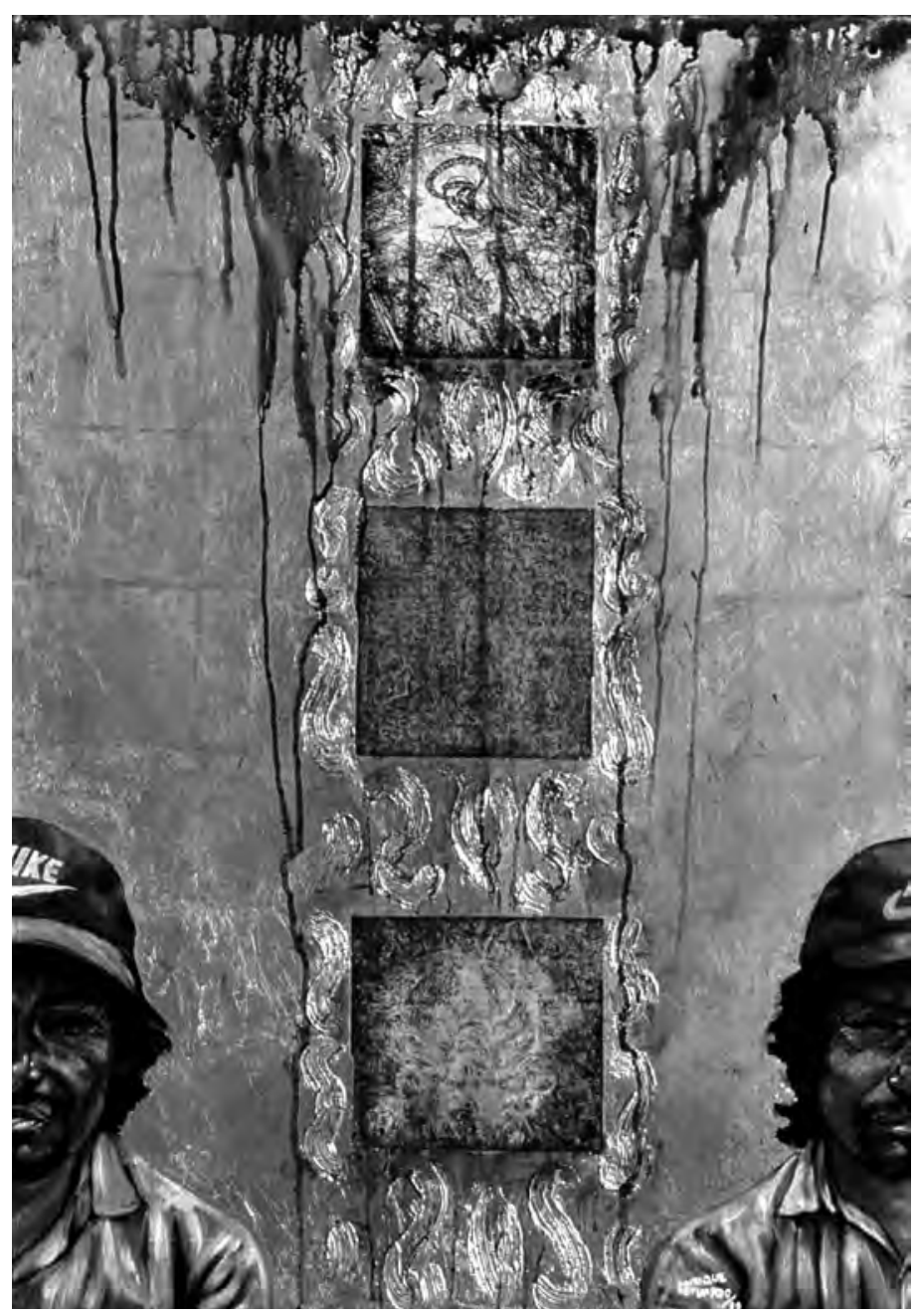

Retablo. Acrílico sobre tela. 1999

* Lic. en Ciencias de la Educación de la UPS. El documento constituye un extracto de su trabajo de grado: Genealogía de la Educación Inicial en el Ecuador: Periodo histórico 1900-2000, dirigido por María Elena Ortiz. 


\section{Introducción}

La educación inicial hoy resulta un espacio de cuidado y aprendizaje en donde se estimula de manera integral a los niños/as desde su nacimiento hasta los seis o siete años, fuera del ámbito familiar. Ésta es considerada en general como un periodo educativo de gran importancia, pues se ve enfocada en promover el desarrollo óptimo de las particularidades físicas y psicológicas de la personalidad, así como de la conducta social que en las sucesivas etapas del desarrollo humano se consolidarán y perfeccionarán. Por otro lado, la consideración de este concepto, obliga a traer a bordo a las diversas modalidades de educación y aprendizaje que han sido destinadas a los niños/as, desde las primeras semanas de vida hasta su ingreso en la escuela primaria. Podemos decir entonces, que la educación inicial ha incluido desde su aparición a programas asistenciales, casas cuna, escuelas maternales, asilos, guarderías, preescolares, jardines de infancia, clases de preprimaria, etcétera. Se debe tener en cuenta que aunque exista una terminología más o menos común para referirse a ese ámbito educativo, tras éste, se halla una gran diversidad de prácticas, sistemas y modalidades, los cuales han ido cambiando y adaptándose a los contextos sociales y concepciones relacionadas a la educación o infancia.

Lógicamente y para responder a las necesidades, las condiciones explícitas del nivel y a la sociedad, este ciclo educativo ha ido desarrollando diferentes estructuras organizativas y pedagógicas, las cuales han sido formuladas, reestructuradas, retomadas o descartadas a través del tiempo, con la clara finalidad de adaptarse a los ideales o pensamientos de las diferentes épocas y realidades de un determinado contexto. Es por ello que podemos decir que la educación o en este caso la educación inicial de manera específica, es una construcción que es y ha sido llevada a cabo de manera progresiva, a lo largo de la historia y cuyos resultados son una suma de diversos factores y visiones sociales.

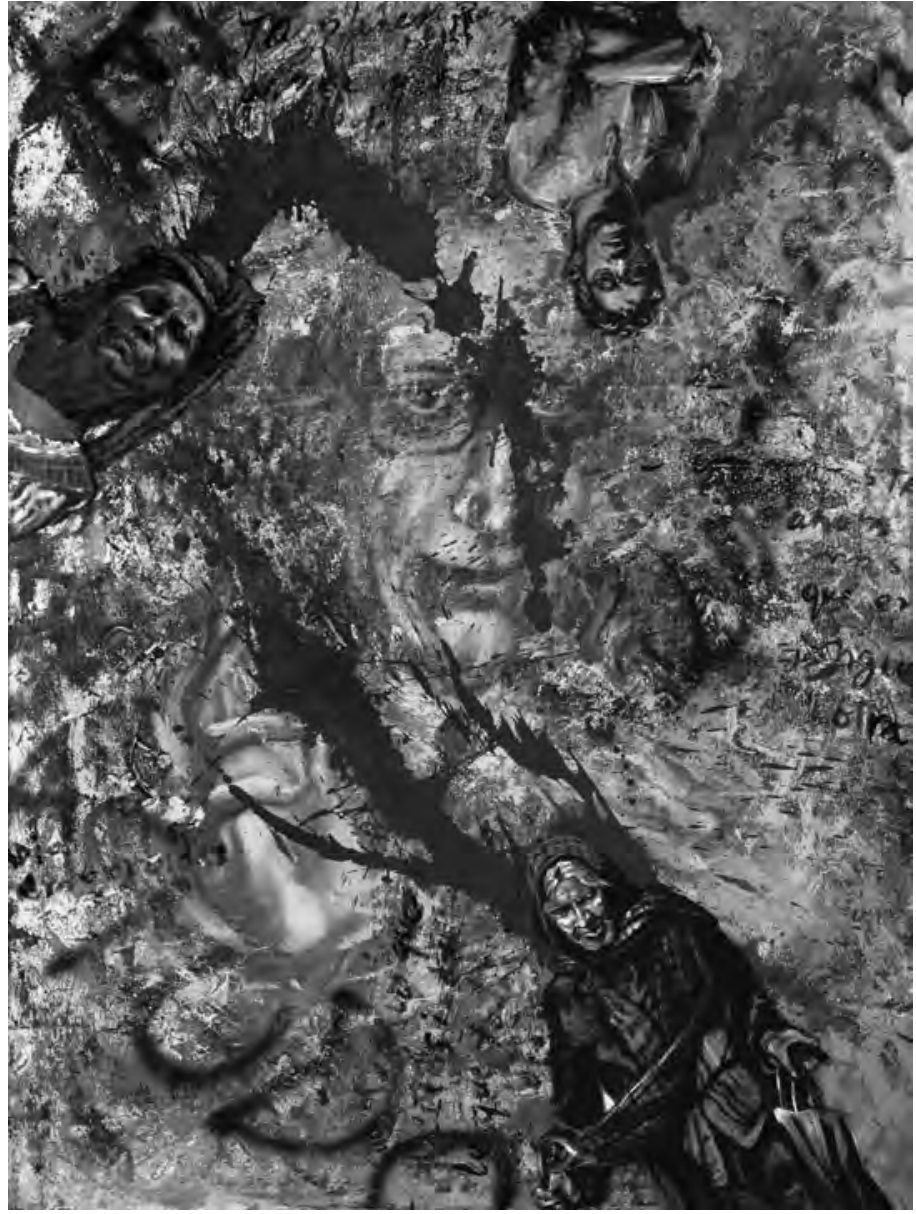

Pregutas sin respuestas. Acrílico sobre tela. 1996

Evidentemente, el caso de la educación inicial ecuatoriana no ha sido ajeno a este proceso de construcción, a estas instituciones y a estas conceptualizaciones históricas, puesto que en el país también se ha vivido un largo y difícil proceso de conformación de este nivel educativo, cuyo inicio fue dado a principios del siglo XX el cual se ha mantenido hasta la época actual en donde se habla con claridad de temáticas relacionadas al desarrollo, ampliación, cobertura y articulación de programas destinados a atender a los niños en edades tempranas. Por ejemplo, el Plan decenal de Educación 2006-2015, coloca a la educación inicial en un puesto prioritario, en 
donde se plantean claros objetivos y metas relacionadas a la universalización de la educación infantil de cero a cinco años de edad. Además, y para respaldar este y otros proyectos relacionados a este nivel educativo, podemos encontrar en el país diferentes estudios relacionados a metodologías, currículos, concepciones o teorías enfocadas a este espacio educativo.

En esta breve aclaración preliminar, se han mencionado diversos conceptos, instituciones y datos, pero es necesario anotar que la procedencia histórica de ellos, a diferencia de otros países, ha sido casi inexplorada y poco cuestionada en el Ecuador. Esto se hace evidente ante la insuficiencia de investigaciones, bibliografías o documentaciones que se encuentren enfocadas a segmentar el entramado político, social y económico de estas concepciones, las cuales sin duda alguna son las que ayudan a comprender el proceso que ha permitido la conformación histórica de la educación inicial en nuestro país.

La situación de desconocimiento del pasado y de escasez de documentos en torno a los procesos iniciales de educativos ecuatorianos, ha implicado que muchas veces en el país no se entienda el por qué la educación del nivel inicial ha sido llevada, trabajada o entendida de determinadas maneras, y además este desconocimiento conlleva a que en muchas ocasiones exista una falta de bases concretas en las cuales los proyectos actuales y a futuro puedan sustentarse $\mathrm{u}$ orientarse.

El estudio aquí planteado nació tomando en cuenta los diferentes elementos ya antes mencionados, por ello se colocó como objetivo principal el conocer la conformación histórica y evolución de la educación inicial ecuatoriana con la idea de aportar a la reflexión teórica e histórica; por lo tanto en éste se revelan aquellos componentes históricos que no han sido profundizados anteriormente dentro de este margen temporal, como son los factores de influencia interna, los modelos teóricos utilizados, las concepciones en torno a la infancia y las fracturas -discontinuidades dadas dentro de la época-. De esta manera, esta investigación ha respondido a la hipótesis centrada en que los elementos sociohistóricos son los que permitieron la conformación de la educación inicial en el Ecuador durante el periodo de 1900 al 2000.

Desde una perspectiva histórica basada en la confección e indagación de archivos y documentos, se cuenta sobre las diversas concepciones, teorías, factores y procesos que se llevaron a cabo para que la educación, destinada a niños/as ecuatorianas de cero a cinco o seis años se haya consolidado en el país. Podemos decir que los elementos vislumbrados en este estudio son de valiosa importancia, ya que los mismos, no sólo permiten una correcta comprensión de la educación inicial, sino también la construcción de un saber histórico real e integral de esta primera etapa educativa, lo cual contribuye a la reflexión del currículo.

\section{Materiales y métodos}

El estudio desarrollado se clasificó como de tipo retrospectivo, pues este se vio comprendiendo en el periodo histórico que abarca desde 1900 (como los primeros indicios de centros infantiles en el Ecuador) hasta el año 2000, temporalidad que ha sido enmarcada dentro del siglo XX. Cabe resaltar que el propósito fundamental fue el mostrar la conformación de la educación inicial dentro de la línea investigada, por lo cual estas fechas fueron sustentadas mediante una detallada y previa revisión bibliográfica.

Las instituciones en las cuales se enfocó el estudio, fueron el Ministerio de Educación por ser el encargado de la educación preescolar y el Ministerio de Bienestar Social por su relación con el cuidado y atención de la infancia.

La investigación se centró en la conformación general de la educación inicial ecuatoriana en el periodo de 1900 al 2000. Por tratarse de un trabajo de carácter histórico, se requirió del análisis documental y bibliográfico por lo cual se hizo uso de documentos nacionales e internacio- 
nales, los cuales permitieron completar datos, pero sin abandonar la línea de interés.

Como se dijo anteriormente y centrándonos con el fin de obtener datos que permitan entender las características históricas y actuales del proceso de educativo inicial en Ecuador, los aspectos o principales líneas de estudio se concentraron en:

- El contexto histórico, social, económico y político durante la formación y consolidación de la educación inicial del Ecuador.

- Los modelos teóricos asumidos en el proceso de conformación histórica de la educación inicial del Ecuador.

- Concepciones de infancia que han sustentado a la educación inicial ecuatoriana.

- Fracturas y discontinuidades dadas en el proceso de conformación de la educación inicial ecuatoriana.

Es importante mencionar que en esta investigación se utilizó como método a la historiografía entendida como una herramienta de trabajo que permite la confección e indagación de los archivos y documentos. Así mismo, el método genealógico en menor medida permitió rastrear la búsqueda de los comienzos y la construcción del mapa de referencia del fenómeno abordado. Cabe mencionar que en esta investigación se ha entendido a la genealogía como un instrumento que se aboca al estudio de los acontecimientos locales, a la percepción o recomposición de sucesos singulares, a la reflexión de la historia y a la visualización particular que permite entender la procedencia de un determinado suceso-objeto y su situación actual.

Otros de los métodos empleados fueron: análisis, síntesis, inducción y deducción, los cuales fueron de vital importancia para completar el proceso de revisión de documentos y procesamiento de datos.

El estudio se ubicó como una investigación cualitativa, puesto que se hizo una descripción de diferentes hechos, con la finalidad de entender el proceso de conformación de la educa-

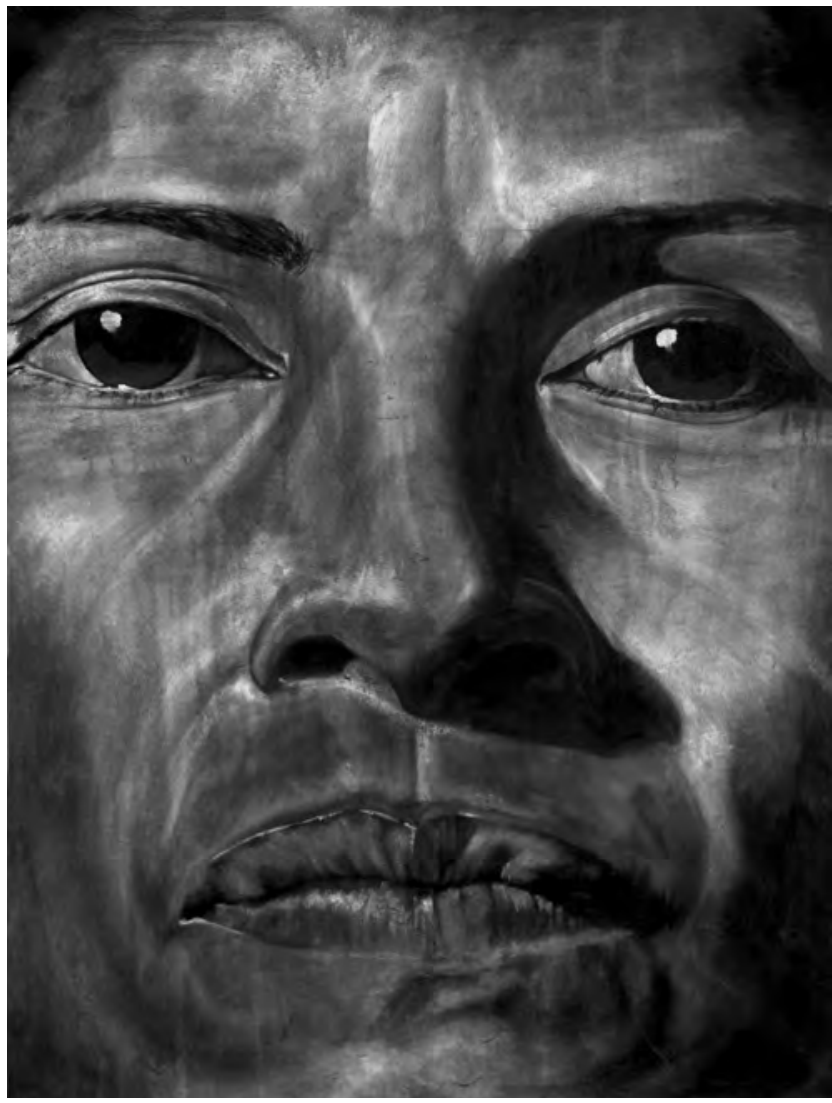

Quilago (32 módulos). Acrílico sobre tela. 2004

ción inicial en el Ecuador. A su vez, se incluyó como técnica principal a la revisión bibliográfica $\mathrm{y}$ al análisis de documentos-textos.

El marco teórico de la investigación estuvo comprendido de tres apartados, los cuales permitieron un adecuado abordaje de contenidos. En la primera sección el estudio se vio enfocado al contexto sociohistórico del Ecuador desde 1900 hasta el año 2000, aquí se indagó la realidad interna del país, en cuanto a sus contextos histórico-sociales, políticos, económicos y educativos dentro del margen temporal establecido. Por otra parte, en un segundo apartado, se realizó un abordaje sobre la asistencia y educación de los infantes en el Ecuador, desde 1900 hasta el año 2000, aquí se puso en evidencia y se dio a entender los dos modelos encami- 


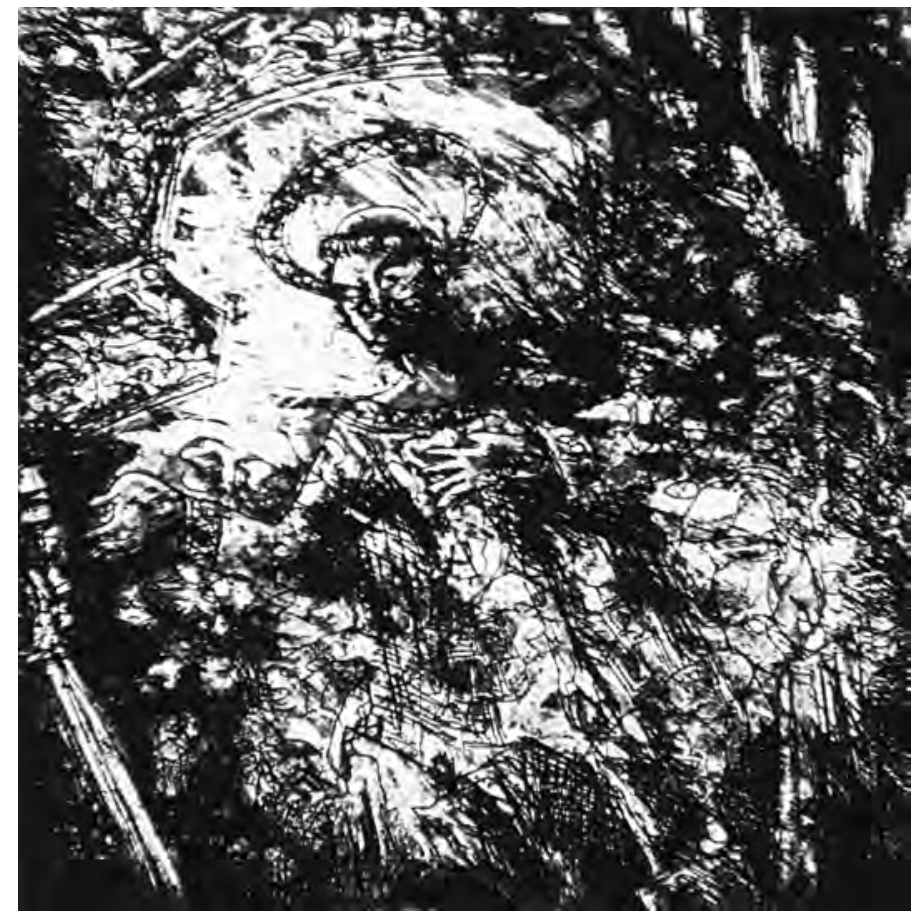

Totem. Grabado. Técnica mixta. 1995

nados en la atención y educación de la infancia. Posteriormente y para finalizar el área teórica, se ejecutó una tercera parte en la cual se efectuó un abordaje sobre los currículos en la educación inicial y los modelos que más influenciaron en el Ecuador.

\section{Resultados}

Del estudio realizado se pudo identificar que la educación inicial llegó al Ecuador a través de un proceso de aculturación promovido por el Cura, de ideología alfarista, Luis Vicente Torres quien importó desde España esta idea educativa. Pero fue el contexto social, económico y político del siglo XX, el que otorgó los componentes y las condiciones necesarias que permitieron el afianzamiento, desarrollo y consolidación del jardín de infantes en el país. En cuanto a los factores que contribuyeron, específicamente, al naci- miento del jardín de infantes ecuatoriano podemos hacer referencia principalmente a la incorporación del liberalismo como sistema nacional, la adopción del laicismo como eje fundamental de la educación, la emancipación e ingreso de la mujer en el mercado laboral e intelectual, la mayor concentración de niños, el desarrollo de cierta conciencia en cuanto a aprovechar el potencial del infante y los diferentes auges económicos suscitados por la exportación cacaotera, bananera y finalmente la petrolera, auges que permitieron a los diferentes gobiernos el destinar mayores recursos a la educación.

También se pudo evidenciar que en la educación inicial ecuatoriana han existido cuatro fracturas y discontinuidades relacionadas a las diferentes concepciones del niño y de cómo éste debe ser educado. La primera visualiza al infante como una planta humana que el proceso educativo desarrollará y hará crecer enderezando su dirección, en el jardín de la vida; la segunda concepción se halla encaminada a una educación que preparará al niño para la vida puesto que lo visualiza como un ser compuesto de cuerpo, mente y espíritu; la tercera ha buscado atender a las necesidades e intereses individuales de cada infante para que éste pueda alcanzar su auto-realización ya que se lo considera como un ser único; finalmente la cuarta concepción, que se mantiene en la actualidad, percibe al niño como un ser integral, en donde la educación juega el papel de estimular el desarrollo de las capacidades físicas, intelectuales, actitudinales y sociales de niños/as.

Es necesario mencionar que el estudio permitió verificar que en un principio la educación inicial ecuatoriana estuvo dividida en tres secciones dirigidas a la atención de los niños/as de tres a cuatro, de cuatro a cinco y de cinco a seis años de edad. En el año de 1938 se da un quiebre que ocasiona que sólo la última sección (niños de cinco a seis años) pase a estar reglamentada por el Ministerio de Educación, dejando que las otras dos secciones (niños de tres a cinco años) sean atendidas por el Ministerio de 
Bienestar Social bajo una matiz totalmente asistencialista, a pesar de que estos niveles hayan sido planteados inicialmente con una perspectiva claramente educativa.

El estudio reveló que en el país han existido dos modelos de servicios destinados para los niños menores de seis años, identificados como: el primero basado en la asistencia y cuidado del menor que se ha encontrado bajo la tutela directa del Ministerio de Bienestar Social; y el segundo con carácter netamente educativo el cual ha sido siempre manejado por el Ministerio de Educación. Asimismo, podemos decir que, el Ministerio de Bienestar Social ha estado guiado primordialmente por una concepción tradicional sobre el niño, en la cual se los ha considerado únicamente como sujetos de protección-cuidado, mientras que el Ministerio de Educación ha evolucionado hasta una actual concepción que concibe al infante como una persona-sujeto de aprendizajes que requiere de un desarrollo integral y un crecimiento adecuado con la ayuda de mediadores. Sin embargo, es importante mencionar que en la actualidad aquellas instituciones que priorizaban exclusivamente el cuidado diario de los niños/as, sin atender al componente de educación han evolucionado a la ejecución de programas que procuran el desarrollo integral con la finalidad de crear una sociedad más justa y equitativa en donde todos los niños puedan recibir el componente educación.

Se llegó a definir que los modelos teóricos y curriculares asumidos durante el proceso de conformación de la educación infantil ecuatoriana fueron los elaborados por Froebel, Montessori y Decroly, cabe mencionar que el primero en llegar al Ecuador fue el froebeliano, pero del estudio realizado se llegó a deducir que la aplicación de las metodologías montessoriana y decroliana no surgió de manera secuencial y ordenada, a pesar de que ambas ideas llegaron al mismo tiempo y por medio de la Primera Misión Alemana, en el año de 1914-1916. La causa de esta falta de orden y secuencia en la aplicación de dichas metodologías se dio porque estas iban sien-

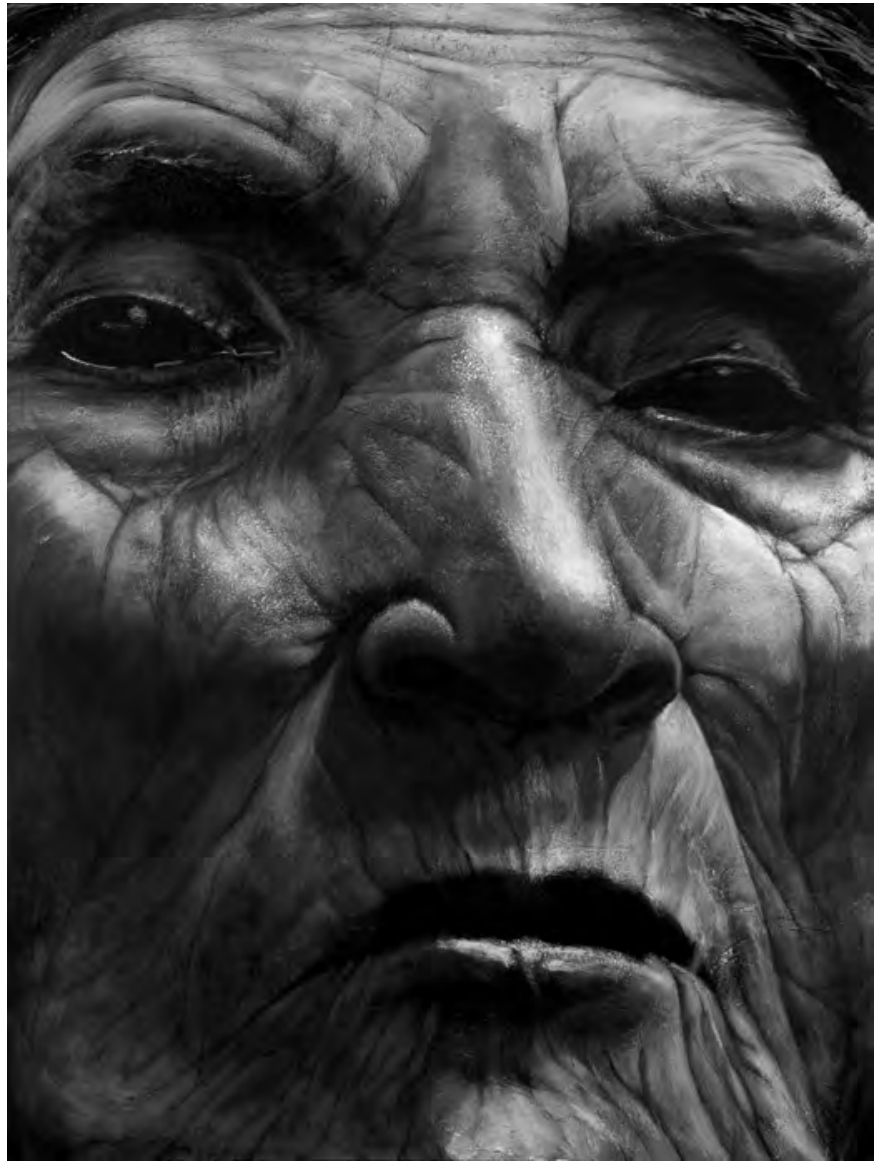

Quilago (32 módulos). Acrílico sobre tela. 2004

do acogidas por los maestros, maestras e instituciones acorde a las necesidades y retos que este nivel fue presentando y más no por el año en las que fueron importadas. Sin embargo, podemos inferir que en determinada época estos tres currículos se trabajan a la par, una evidencia que nos hace suponer esto, es que en el Plan de Organización, trabajo y reglamento de Jardines de Infantes del año 1943, se señala que el desarrollo sensorial debe ser técnicamente dirigido, asegurando al niño su libertad, espontaneidad mediante los fundamentos científicos de Froebel, Decroly y Montessori. Esta idea, aunque su debida aplicación es difícil de confirmar por la falta de otros documentos o de informes que 
muestren evidencias exactas sobre estos procesos, permitió determinar que en lo relacionado a metodologías no existieron fracturas ni discontinuidades.

A partir de la revisión de los elementos y fundamentos propuestos en los currículos froebeliano, montessoriano y decroliano, se pudo observar que en la actualidad persisten muchos de ellos en la educación ecuatoriana, por su validez permanente, como son los que se describen a continuación:

- Froebel: La organización de grupos mixtos, la necesidad de poseer una concepción sobre la vida y el hombre ante cualquier planteamiento educativo, la importancia del ambiente escolar en el desarrollo del infante, la organización de zonas externas y el trabajo en las mismas, la realización de actividades en relación a los materiales.

- Montessori: La educación activa, la consideración del educador como preparador del ambiente, la preparación de mobiliarios acorde a las características físicas del niño, las actividades para la vida práctica, la organización del tiempo diario, la incorporación de materiales creados por los propios alumnos, el rechazo a los premios

Cuadro 1. Aplicación de las metodologías en el jardín de infantes

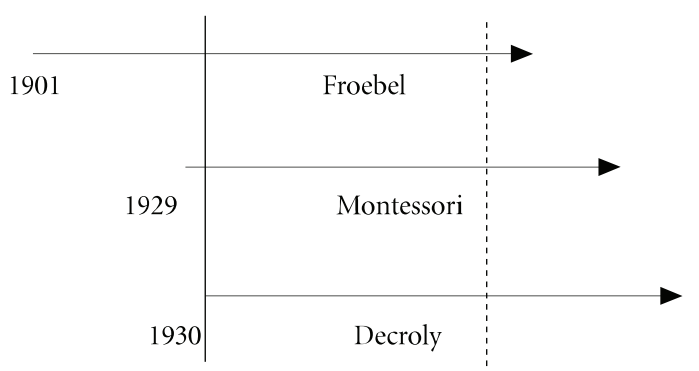

y a los castigos.

- Decroly: La conformación de grupos homogéneos de niños, el trabajo educativo correlacionado que se plantea con la familia, las actividades surgidas de situaciones de la vida diaria y de los intereses del alumno, la participación de los niños en la ordenación y decoración de los ambientes, el ir de lo concreto a lo lejano o de lo simple a lo compuesto y de lo conocido a lo desconocido.

Se concluyó que los diferentes modelos curriculares y las diversas concepciones sobre infancia y educación son producto de los procesos de construcción que se han dado a lo largo de la historia de la humanidad, es decir, son el resultado de tradiciones, visiones, necesidades, acciones y proyectos sociales de un determinado contexto, es por ello que el currículo no puede ser entendido como un componente estático e incambiable puesto que este tiene, como se dijo anteriormente, que adecuarse a las necesidades sociales, políticas, económicas, educativas del grupo al que va dirigido.

A raíz de esta investigación se pudo constatar que el jardín de infantes ecuatoriano ha mantenido a lo largo de los años una dependencia cultural en relación a los modelos curriculares elaborados en los países de Occidente, esta dependencia ha implicado que en algunos momentos los contenidos, actividades o recursos posean un cierto grado de desvinculación con el medio ecuatoriano, ya que dichos currículos (froebeliano, montessoriano y decroliano) respondían a realidades, culturas y entornos totalmente diferentes al nuestro.

Por otra parte se comprobó que antes de que se plantee el Plan Decenal de Educación, no había existido en el país documento alguno en el que se plantee, claramente, la necesidad de universalizar, ampliar, articular y desarrollar de manera adecuada a este nivel educativo, a pesar de que la educación inicial ya venía funcionando en el país por más de un siglo. Por ello se 
puede decir que la incorporación del Plan Decenal y su propuesta sobre la educación de los más pequeños ha sido el resultado de varios convenios firmados por el Ecuador, que buscan alcanzar una educación para todos, resta decir que el éste plan ha ayudado a que este nivel de educación sea considerado desde su justa dimensión y que se le otorgue la verdadera importancia que posee en el desarrollo social y en la formación humana.

\section{Discusión}

Sin duda alguna el recorrido histórico que ha tenido la educación inicial con todos sus aciertos y equivocaciones ha servido para que en la actualidad sigamos buscando nuevas formas de desarrollar la educación y de atender a las necesidades de la población infantil ecuatoriana, el objetivo ahora se halla encaminado a la aplicación de currículos abiertos, flexible e integrales, así mismo a la construcción de un ambiente educativo de calidad y equitativo, que se encuentre al alcance de todos los niños y niñas.

\section{Bibliografía}

- AGOGLIA, Rodolfo: Historiografía Ecuatoriana, 1ra. Edición. Quito: Corporación Editora Nacional. 1985

- BALL J., Stephen: Foucault y la Educación (Disciplinas y saber), 2da. Edición. Madrid: Ediciones Morata. 1994

- BRAVO, Luis: El sistema Decrolyano, 1ra. Edición. Cuenca: Editorial El Tiempo. Ecuador. 1942

- CLARKE - STEWART, Alison: Guarderías y cuidado infantil, 1ra. Edición. Madrid: Ediciones Morata. 1984

- COlMENAR, Carmen: "Génesis de la educación infantil en la sociedad Occidental". En Revista Complutense de Educación, vol. 6, número 1, Madrid: Universidad Complutense. 1995

- FLÓREZ, Rafael: Hacia una pedagogía del conocimiento. 1ra. Edición. Bogotá: Editorial Panamericana Formas. 1997
- GASSÓ, Anna: La educación infantil. 1era. Edición. Barcelona: Ediciones Ceac. España. 2004

- GÚTIEZ CUEVAS, Pilar: "La educación infantil: modelos de atención a la infancia", Revista Complutense de Educación, vol. 6, Número 1. Madrid: Universidad Complutense. España. 1995

- LÓPEZ, Lola: Educación Preescolar, 1era. Edición, Buenos Aires: Editorial Troquel. 1970

- MACHADO, Ana Luisa: Educación para todos en América Latina-Informe Regional de Monitoreo de EPT 2003, 1ra. Santiago: Edición, Editorial Trineo. 2004

- MIALARET, Gastón: La educación pre-escolar en el mundo, UNESCO, París-Francia. 1976

- Ministerio de Bienestar Social, Protección y rehabilitación de menores en el Ecuador, Secretaría General de Planificación. Quito-Ecuador. 1985

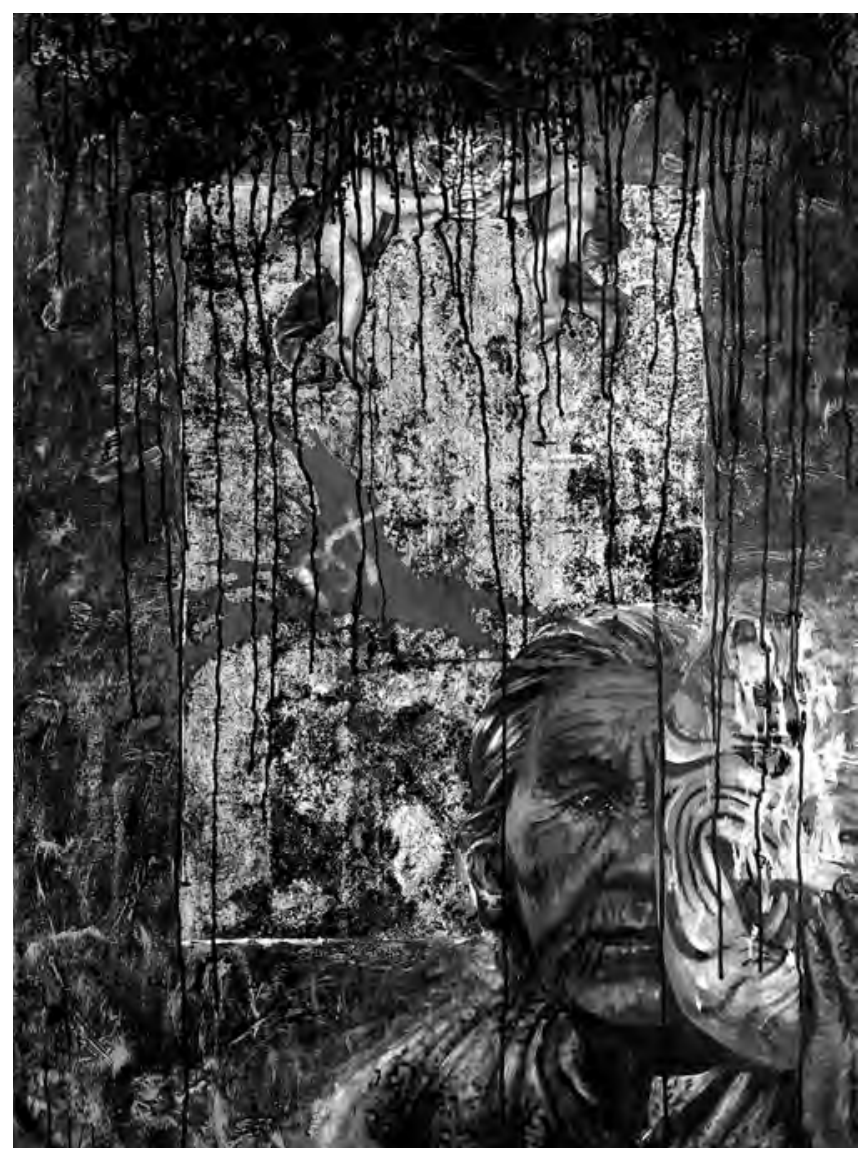

Proceso del olvido II. Acrílico sobre tela. 1996 
- Ministerio de Educación y Cultura: Hacia el Plan Decenal de Educación del Ecuador, 2006-2015. MEC, Quito-Ecuador. 2006

- Ministerio de Instrucción Pública del Ecuador, Informes a la Nación. Imprenta Nacional. QuitoEcuador.

- Ministerio de Educación y Cultura, Serie pedagógica Número tres: Educación Inicial, 1ra. Edición, DINAMEP. Quito-Ecuador. 2002

- Ministerio de Educación y Cultura, Tercera Consulta Nacional Educación Siglo XXI-Documento Base. MEC. Quito-Ecuador. 2004

- MORA ORTEGA, Luis: Política y Sociedad, Ecuador: 1830-1980, 1ra. Edición, Quito: Gráficas Señal. 1980.

- PALADINES, Carlos: Historia de la educación y del pensamiento pedagógico Ecuatorianos, 3ra. Edición, Loja: Editorial de la Universidad Técnica Particular de Loja. 2005

- PALADINES, Carlos: Arte y Cultura en el Ecuador 1830-1980, 1ra. Edición. Quito: Corporación Editora Nacional. 1980

- PERALTA, María Victoria: El Currículo en el Jardín Infantil, 3ra. Edición. Santiago: Editorial Andrés Bello. 1993

- EL COMERCIO, El Ecuador en el siglo XX, Editorial Publitécnica, 1era. Edición. Quito-Ecuador. 1981

- REYES, Oscar Efrén: Breve historia general del Ecuador, 1era. Edición. Quito: Talleres gráficos Nacionales, Tercera Edición. 1949

- RUBIO ORBE, Gonzalo: "Las corrientes pedagógicas que han dominado en el Ecuador desde la fundación de los Normales". En Revista Ecuatoriana de Educación, Número 16, marzo-abril. Casa de la Cultura Ecuatoriana. Quito-Ecuador. 1951
- GIMENO SACRISTÁN, José: El Alumno como invención, 1era. Edición, Madrid: Ediciones Morata. 2003

- TOBAR, Julio: Evolución de las ideas pedagógicas en el Ecuador, 1ra. Edición, Quito: IMP, Universidad Central. 1954

- TORRES, Vicente Luis: Manual del Kindergarten, 1ra. Edición, Cataluña: Imprenta Elzeviriana. España. 1908

- UZCATEGUI, Emilio: Antología Pedagógica Ecuatoriana, 1ra. Edición. Quito: Editorial Universitaria. 1984.

- UZCATEGUI, Emilio: Historia de la educación en Hispanoamérica, 1ra. Edición. Quito: Editorial Universitaria. 1975

- VARELA, Julia: Genealogía de la escuela, Universidad de la Laguna, TEMPORADA Número ocho. 1986.

\section{Bibliografía de Internet}

- AYALA MORA Enrique, Ecuador raíces del presente, Diario la Hora, consultado el 27 de junio del 2007 en: http://www.dlh.lahora.com.ec/ paginas/historia/historia10b.htm

- RODRÍGUEZ, María del Mar: Las representaciones del cambio educativo, Revista electrónica de investigación educativa, No 2- Vol. 2, 2000. Consultado el día 18 de Noviembre de 2006 en: htt$\mathrm{p}: / /$ radie. Uabc.mx/vol2no2/contenido-romero.html

- TANI, Rubén: Arqueología de la lectura y el sujeto, Revista electrónica de filosofía, № 32. Consultado el 17 de Noviembre de 2006 en: http://serbal.pntic.mec.es/-cmunoz11/index.htlm 